\section{Chemotherapy in Scarlet Fever}

Q.-Should cases of scarlet fever be treated by penicillin or sulphonamides?

A.-Most clinicians of experience have not been impressed with the value of sulphonamides in scarlet fever. They have, of course, no direct effect against toxaemia, and evidence of appreciable improvement in the local throat condition is lacking. It is believed that there is a lessened tendency to secondary septic complications-for example, otitis mediabut these occurrences are so uncommon to-day that it is hard to get acceptable statistical evidence in support of this. The writer is more impressed with the value of penicillin and uses it almost exclusively, although occasionally combined with sulphonamides. The usual course is of seven days, comprising an initial injection of 500,000 units of the crystalline preparation followed by a daily maintenance dose of 300,000 units of procaine penicillin for the average child or adolescent. If the case is septic the dose should be substantially increased and the spacing shortened. If toxaemia is present antitoxic serum is invaluable combined if desired, with penicillin therapy.

\section{Controlled Respiration in Bulbar Poliomyelitis}

Q. -What place has curarization and controlled respiration in the treatment of respiratory paralysis in poliomyelitis pending the availability of an iron lung or other mechanical respirator? I recently had a rapidly fatal case (in 48 hours from onset) on board ship, and I wondered if controlled respiration might have saved the patient.

A.- Controlled (positive-pressure) respiration is entirely suitable for cases of poliomyelitis requiring artificial respiration, especially when there is paralysis of swallowing, and has recently been advocated by Lassen ${ }^{1}$ and Crampton Smith et al. ${ }^{2}$ An intratracheal cuffed tube may be used for 6-12 hours, but for longer periods a cuffed tracheotomy tube is necessary : curare is not usually required except in cases of tetanus, as reported by Shackleton. ${ }^{3}$ A simple mechanical pump to maintain positive-pressure breathing such as was used by Crampton Smith and his colleagues might be very suitable for use on board ship where tank respirators are not available.

$$
\begin{array}{ll}
\multicolumn{3}{c}{\text { RefERENCES }} \\
1 \text { Lancet, 1953. 1, } 37 . \\
2 \text { Ibid., 1954, 1. } 939 . \\
3 \text { Ibid., 1954, 2, } 155 .
\end{array}
$$

\section{Duration of Pregnancy}

Q.-How reliable is the height of the uterus in estimating the duration of pregnancy in an uncomplicated case? I was taught that the pregnant uterus became palpable at the symphysis pubis at the 12th week, but quite often it can be felt two or three weeks earlier. What is the best method of estimating the age of the pregnancy when there is doubt about the date?

A.- Estimation of the duration of pregnancy by the height of the uterine fundus alone is a very rough method, but is rather more reliable between the 16th and 36th weeks than at other times. Although the fundus is ordinarily palpable just above the symphysis pubis at about the 12 th week, it can often be felt abdominally earlier than this. Indeed, in thin women with relaxed abdominal muscles the top of the normal non-pregnant uterus can sometimes be felt suprapubically. The height of the uterus is affected by all manner of factors-and not least by a loaded rectum and full bladder. Moreover, some uteri are longer and narrower than others, so the experienced obstetrician usually (and often subconsciously) makes an allowance for width when calculating from the height. Thus, provided he carries out a bimanual examination, he is usually able to make a clear distinction between an 8,12 , and 16 weeks pregnancy.

From the 26th week onwards, assessment of duration of pregnancy is sometimes best made by judging the size of the foetal head, but this again requires experience. Near term, other factors can be taken into consideration-the entry of the presenting part into the pelvis, effacement of the cervix, and the sensitivity of the uterus. All these clinical methods, however, are obviously uncertain, because the size of normal babies varies enormously, while the size of the uterus depends also on the amount of liquor present. Again, there is a natural tendency to estimate the height and size of the uterus in relation to the size of the mother or the length of her trunk - so in a tall woman it is easy to underestimate the duration of pregnancy and vice versa.

Radiological estimation of foetal maturity is equally. unreliable, for it depends on the size of the baby in whole or in part, the general deposition of calcium in the skeleton, and the time at which various centres of ossification appear -and all of these vary widely within normal limits. The time at which a woman experiences quickening is also an uncertain guide.

In any particular case, reliance should not be placed on any single observation but on all the evidence which can be assembled. In this respect it is sometimes helpful in the late weeks to refer back to earlier estimates of the duration of pregnancy. The expert obstetrician, taking into account all the findings, both clinical and radiological, often underestimates or overestimates the duration of pregnancy by at least two weeks, so, when the date of the last menstrual period is known, he usually prefers to rely on this rather than on physical signs.

\section{The Family Ghost}

Q.-What are the cause and treatment of the creaking of the joints of a young man whose state of health is good ind whose only other complaint is alopecia? When going upstairs or along a corridor he sounds like the family ghost.

A.- This condition has no known cause. It is probable. though of course unproved, that the creaking -arises in the sheaths of the muscles and tendons around the joints, and not in the joints themselves. In any case, this creaking appears to be of no untoward significance. It is not a warning of any form of arthritis, and, though it causes some patients a great deal of alarm, this alarm is unjustified. There is, unfortunately, no useful treatment which can be recommended.

\section{Corrections}

The acknowledgment at the end of the article entitled "The Collagenous Changes in the Intervertebral Disk with Age and Their Effect on Its Elasticity" by Mr. A. Naylor, Dr. F. Happy, and Mr. T. Macrae (Journal, September 4, p. 570) should have read: "Use of equipment provided by the Wool Textile Research Council at the Bradford Technical College for work on the structure of wool is gratefully acknowledged."

In Table III of Professor C. B. Perry and Dr. W. A. Gillespie's article "Intramuscular Benzathene Penicillin in the Prophylaxis of Streptococcal Infection in Rheumatic Children " (Journal. September 25, p. 729) the figure for the total swabs in March to June, 1953, should have been 432 and the percentage of positive swabs 43.1 .

We regret that an error was made in the legends for the figures (reproduced on the special plate) which accompanied the paper by Dr. H. B. Fell, Sir Edward Mellanby, and Dr. S. R. Pelc (Journal, September 11, p. 611), entitled "Influence of Excess Vitamin A on the Sulphate Metabolism of Chick Ectoderm Grown in Vitro." Figs. $1 a$ and $2 a$ were stained (haematoxylin) sections $(\times 600)$ with autoradiographs and not unstained sections, phase contrast. The sections shown in Figs. $1 b$ and $2 b$ were not the same sections as Figs. $1 a$ and $2 a$, but were adjacent.

Al! communications with regard to editorial business should be addressed to THE EDITOR, British MEdical Journal, B.M.A. House. TaVistock SQUARE. LONDON, W.C.1. TELEPHONE: EUSTON 4499. TELEGRAMS Aitiology, Westcent, London. ORIGINAL ARTICLES AND LETTERS Medical Journal alone unless the contrary be stated. uters desiring REPRINTS she Authors desiring REPRINTS should communicate with the Publishing MVERTISEMENTS she This DERTSEM Should be addressed to the Advertisement Manager B.M.A. House. Tavistock Square, London, W.C.1 (hours 9 a.m. to 5 p.m.) TELEPHONE : EUSTON 4499. TELEGRAMS : Britmedads, Westcont. London the Association TELEPHONE: EUSTON 4499 to the SECRETARY O the Association.

B.M A SCOTtish OfFice: 7, Drumsheugh Gardens, Edinburgh. 